\title{
Microstructural Characterization of Ceramic Floor Tiles with the Incorporation of Wastes from Ceramic Tile Industries
}

\author{
Carmeane Efftinga,", Marilena Valadares Folgueras ${ }^{\mathrm{b}}$, Saulo Güths ${ }^{\mathrm{c}}$, Orestes Estevam Alarcon ${ }^{\mathrm{c}}$ \\ ${ }^{a}$ Instituto Superior Tupy - IST, Sociedade Educacional de Santa Catarina - SOCIESC, \\ Rua Albano Schmidt, 3333, CEP 89206-001, Joinville, SC, Brasil \\ ${ }^{\mathrm{b}}$ Universidade do Estado de Santa Catarina - UDESC, Joinville, SC, Brasil \\ 'Universidade Federal de Santa Catarina - UFSC, Florianópolis, SC, Brasil
}

Received: December 7, 2009; Revised: July 14, 2010

\begin{abstract}
Ceramic floor tiles are widely used in buildings. In places where people are bare feet, the thermal sensation of cold or hot depends on the environmental conditions and material properties including its microstructure and crustiness surface. The introduction of the crustiness surface on the ceramic floor tiles interfere in the contact temperature and also it can be an strategy to obtain ceramic tiles more comfortable. In this work, porous ceramic tiles were obtained by pressing an industrial atomized ceramic powder incorporated with refractory raw material (residue from porcelainized stoneware tile polishing) and changing firing temperature. Raw materials and obtained compacted samples were evaluated by chemical analysis, scanning electron microscopy (SEM), energy-dispersive spectrometry (EDS), thermogravimetric analysis (TGA), and differential thermal analysis (DTA). Thermal (thermal conductivity and effusivity) and physical (porosity) measurements were also evaluated.
\end{abstract}

Keywords: ceramic floor tiles, microstructure, thermal and mechanical properties, porosity

\section{Introduction}

Ceramic floor tiles are widely used in buildings. They have aesthetical and technical functions. Among the technical functions floor thermal insulation it became very important in buildings with human occupation where thermal comfort is required. The human body can be considered as a "thermal machine" which generates a heat amount between 100 and $1000 \mathrm{~W}$ according to the performed activity. As we have hot blood the heat generates by the human body must be dissipated to maintain constant the human body temperature. The thermal regulators mechanisms are responsible for this task. Many are the elements that contribute for the comfort sensation and they are characterized by the physiological and psychological response intensities of an individual to the environment around him ${ }^{1}$. The main environmental variables are: the air temperature, the relative moisture, the wind speed and the radiant temperature ${ }^{2,3}$. However, we can be subjected to some kind of localized uncomforting like for example the feet contact when the floor is hot or cold. Research works related to the people response with respect to the floor temperature revealed that when people are footwear the finished pavement material is not important therefore in places where people are bare feet this aspect becomes significant. The uncomforting can be characterized by heated floor surfaces in external environments which are exposed to sun radiation (swimming pools areas) or by cold floor surfaces in internal environments (bed rooms, path rooms). The thermal sensation is related to the skin temperature, in this case with the feet surfaces attached or in contact to the pavement. The contact temperature can be correlated by a property named thermal effusivity. As lower is the pavement thermal effusivity as close is the contact temperature to the human body temperature resulting in a best comfort. In this context, this work has as objective to understand the interaction of human bear feet in contact with porous ceramic floor tiles in order to design thermally comfortable high performance ceramic products. The thermal effusivity is directly correlated to the thermal conductivity and the material density. Materials with low thermal conductivities and densities can be obtained by porous inclusion. It can consider as a general rule that thermal conductivity of porous materials decreases as the porosity increases ${ }^{4}$. In this work, porous ceramic floor tiles were obtained by pressing ( $30 \mathrm{MPa})$ an industrial atomized ceramic powder incorporated with $20 \mathrm{wt}$. (\%) of a residue provenient from the polishing process of porcelainized stoneware tiles and variation of firing temperature.

\section{Materials and Methods}

An atomized ceramic powder used in the production of singlefired unglazed floor tiles and a residue provenient from the polishing process of porcelainized stoneware tiles were chosen. The raw materials were chemically analyzed (Table 1) by X-ray fluorescence spectroscopy (XRF). The ceramic powder was prepared in a pilot by wet grinding in a discontinuous ball mill and by spray drying of the resulting deflocculated concentrated aqueous suspension. With the aim of verifying the influence of the porosity on the thermal behavior of ceramic floor tiles the spray-dried ceramic powder was compacted at $30 \mathrm{MPa}$ by means of an automatic hydraulic press. With the same finality, additional ceramic bodies containing atomized ceramic powders and $20 \mathrm{wt}$. (\%) of residue and also pure residue were wet homogenized in a ball mill so that the obtained mixtures, after desegregated and humidified ranging from 7 to $10 \mathrm{wt}$. (\%), were compacted at $30 \mathrm{MPa}$. For the measurements, compacted samples with nominal dimensions of $58 \times 126 \times 10 \mathrm{~mm}$ were used. The compacted samples were then dried at $110^{\circ} \mathrm{C}$ for 2 hours and subsequently fired in a fast-cycle laboratory roll furnace in the $950-1250{ }^{\circ} \mathrm{C}$ temperature range according to a single fast-firing cycle of about 55 minutes. Apparent $\left(\rho_{\mathrm{a}}\right)$ and real $\left(\rho_{\mathrm{r}}\right)$ densities of fired samples were measured by the Archimede's principle with mercury immersion at $25^{\circ} \mathrm{C}$ and 
by using a helium pycnometer, respectively. In order to determine the porosity $(P)$ of fired samples Equation 1 was applied.

$$
P=1-\frac{\rho_{a}}{\rho_{r}}
$$

Heat-treated samples were coated with a thin Au film for scanning electron microscopy (SEM) observations. To investigate the crystalline phases formed during heat-treatments, samples were analyzed with a powder diffractometer (XRD) in an interval of 10 to $70^{\circ} \mathrm{C}$, using a $\mathrm{Cu}$ tube and a scanning rate of $2{ }^{\circ} \mathrm{C} / \mathrm{min}$. Bending strength $\left(\sigma_{f}\right)$ of fired samples was performed in a test machine according to ISO 10545-4. Thermal conductivity was carried out according to ISO 8301. Measurements were performed at $25^{\circ} \mathrm{C}$ so that the measurement uncertainty was estimated in about $3 \%$. Effusivity was calculated from the thermal conductivity and density measurements. The specific heat was obtained from the literature.

\section{Results and Discussion}

The morphology of the two materials were studied through the scanning electron microscopy (SEM) technique. According to the SEM micrograph and performed measurements, the atomized powder is characterized by a heterogeneity in the shape and size of the granules as illustrated in the Figure 1a. Moreover, the granules of the atomized powder are characterized by spherical particles due to the atomization process and residue particles present much finer granulation than the atomized powder Figure 2a. The energydispersive spectrometry (EDS) technique was used to verify the chemical composition of these agglomerates, where the found elements were $\mathrm{Si}, \mathrm{Al}, \mathrm{Mg}, \mathrm{Fe}$ e K. Figure $2 \mathrm{~b}$ shows the microstructure for a ceramic sample compacted at $30 \mathrm{MPa}$ and fired at $1100{ }^{\circ} \mathrm{C}$, it can be seen that the material consists of segregated areas where the residue is concentrated immersed in a matrix that is based on ceramic body.

Some atomized particles have a central cavity (Figure 1a), which is characteristic of the process of atomization, and in some cases can be considered a defect. These clusters are broken during handling (Figure 1b), which shows that present bending strength suitable for use in the process of compaction which should promote better distribution of ceramic mass in the matrix by flowing of the cluster and rupture between them, explaining the proper distribution of ceramic mass in the matrix compacted (Figure 2b).

The clusters of atomized mass when mixed with particles of residue, resulting in a formation where the residue is accommodated in the empty spaces formed between the clusters (Figure 2a). During the process of compaction, these clusters are eliminated generating a continuous and compact microstructure. After sintering (Figure 2b), it was observed the presence of regions with the highest concentration of residue surrounded by ceramic body (segregation).

Table 1. Chemical composition of ceramic powder and residue.

\begin{tabular}{|c|c|c|c|c|c|c|c|c|c|c|c|}
\hline Sample & $\begin{array}{c}\mathrm{SiO}_{2} \\
(\%)\end{array}$ & $\begin{array}{c}\mathrm{Al}_{2} \mathrm{O}_{3} \\
(\%)\end{array}$ & $\begin{array}{c}\mathrm{Fe}_{2} \mathrm{O}_{3} \\
(\%)\end{array}$ & $\begin{array}{c}\mathrm{CaO} \\
(\%)\end{array}$ & $\begin{array}{c}\mathrm{Na}_{2} \mathrm{O} \\
(\%)\end{array}$ & $\begin{array}{c}\mathrm{K}_{2} \mathrm{O} \\
(\%)\end{array}$ & $\begin{array}{c}\mathrm{MnO} \\
(\%)\end{array}$ & $\begin{array}{l}\mathrm{TiO}_{2} \\
(\%)\end{array}$ & $\begin{array}{c}\mathrm{MgO} \\
(\%)\end{array}$ & $\begin{array}{c}\mathrm{P}_{2} \mathrm{O}_{5} \\
(\%)\end{array}$ & $\begin{array}{l}\mathrm{PF} \\
(\%)\end{array}$ \\
\hline Ceramic Powder & 63.36 & 18.20 & 2.77 & 1.74 & 0.34 & 3.87 & 0.02 & 0.80 & 2.04 & 0.05 & 6.80 \\
\hline Residue & 64.20 & 18.32 & 0.65 & 1.09 & 1.95 & 1.84 & 0.06 & 0.26 & 6.63 & 0.06 & 4.96 \\
\hline
\end{tabular}

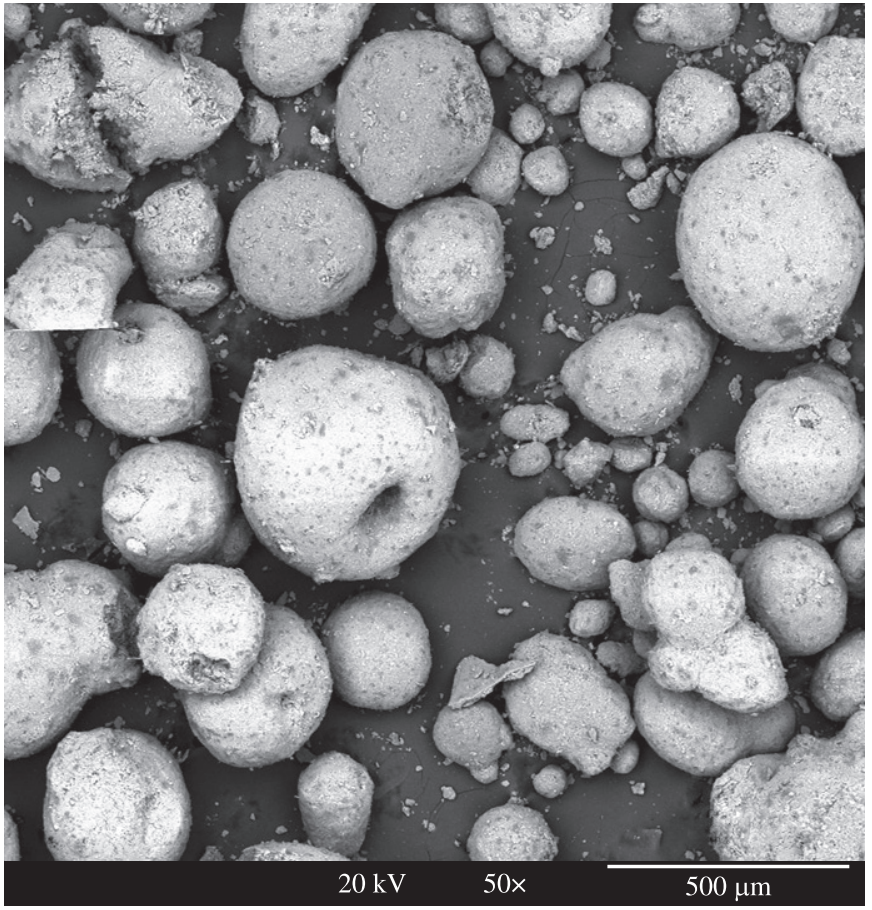

(a)

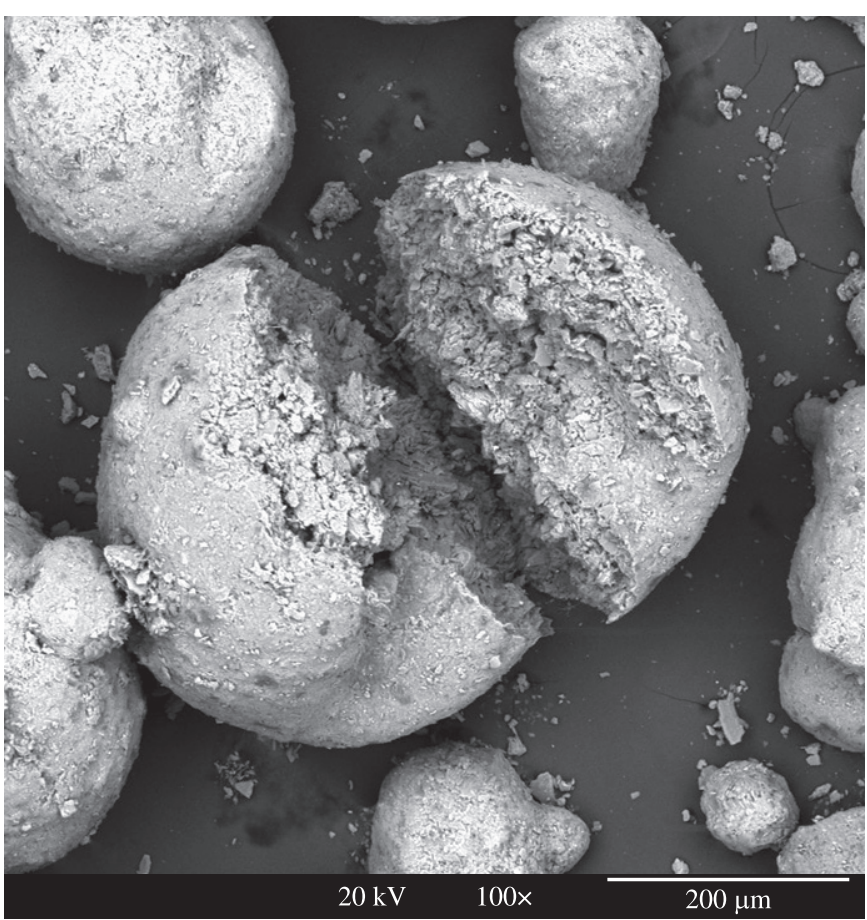

(b)

Figure 1. SEM micrographs of atomized ceramic powder and characteristic of fracture. 
Table 1 shows the chemical composition of the ceramic powder used in this work. From the table it can be seen that the constituent oxides are typical of ceramic bodies employed for the manufacture of ceramic floor tiles.

\subsection{Transformation of phase during burning}

Ceramic floor tiles with $20 \mathrm{wt}$. (\%) residue (provenient from the polishing process of porcelainized stoneware tiles) incorporation were obtained and characterized. Figure 3 shows the XRD of a sample with 20 wt. (\%) of residue as received (mixture) and fired at $1170{ }^{\circ} \mathrm{C}$. Crystalline phases are typical of ceramic floor tiles. However, cordierite was also formed (Figure 3 ) and it can improve, among other properties, the mechanical strength. In fact, as shows Table 2, bending strength $\left(\sigma_{\mathrm{f}}\right)$ for samples with $20 \mathrm{wt}$. (\%) residue (B) increased as the firing temperature was increased up to $1100{ }^{\circ} \mathrm{C}$. For higher firing temperatures bending strength decreases since porosity increased. On the other hand, as the porosity increased thermal conductivity decreased as shown in Table 2 . In this case, it

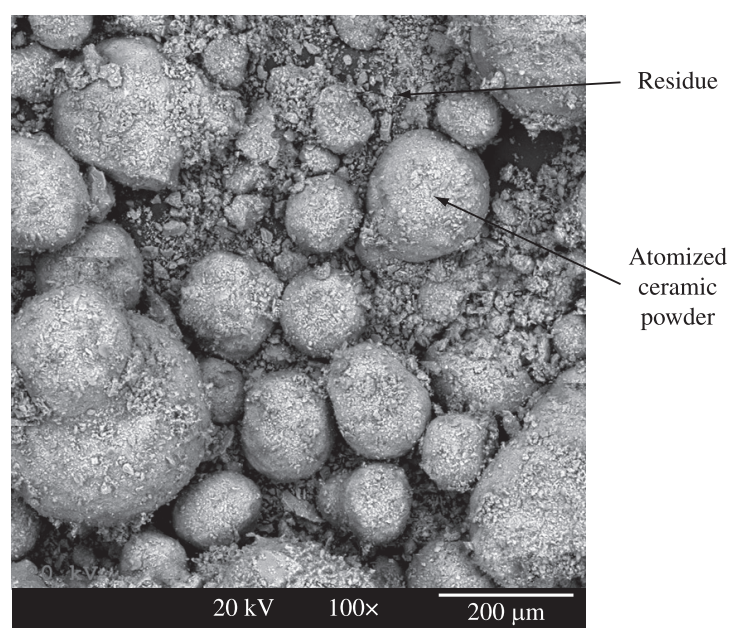

(a)

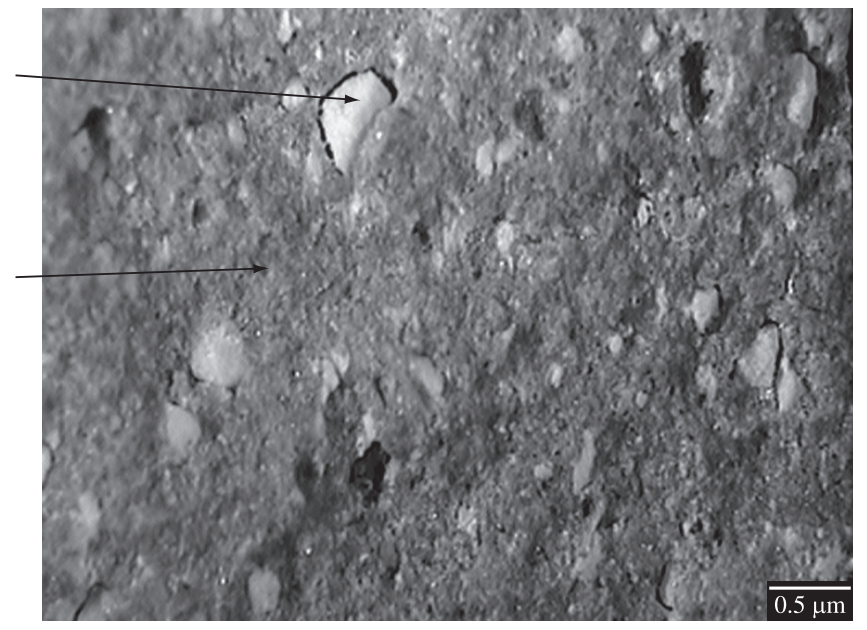

(b)

Figure 2. SEM micrographs of the mixture of atomized ceramic powder with $20 \mathrm{wt}$. (\%) residue: a) before compaction and b) after compaction and firing to $1100{ }^{\circ} \mathrm{C}$.

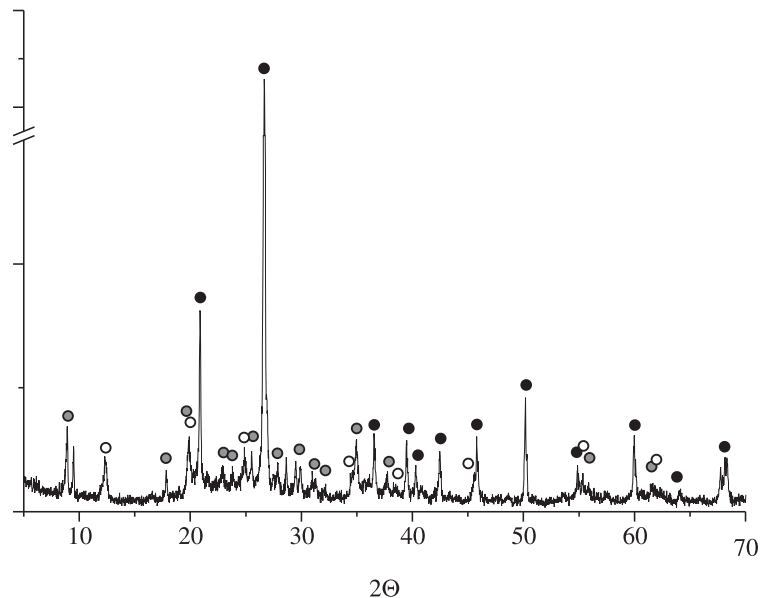

(a)

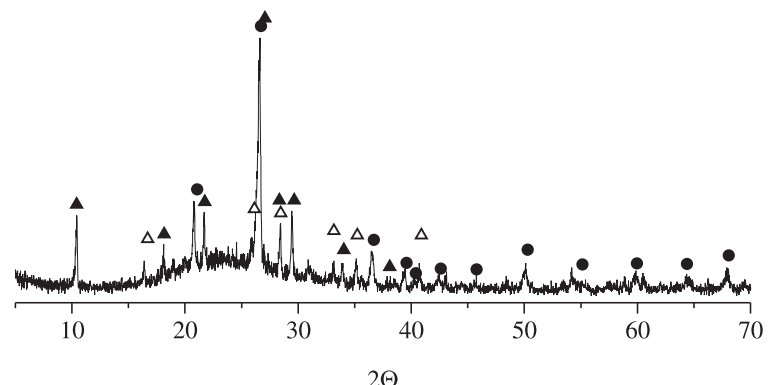

(b)

Figure 3. XRD of samples with 20 wt. (\%) residue: a) Raw materials and b) Fired at $1170{ }^{\circ} \mathrm{C}$.

Table 2. Measured properties on: (A) Atomized ceramic powder; (B) Ceramic powder with 20 wt. (\%) residue incorporation and (C) $100 \%$ residue. T: Firing temperature; P: Porosity; $\sigma_{\mathrm{f}}$ : Bending strength; $\lambda$ : Thermal conductivity and $\varepsilon$ : Thermal effusivity.

\begin{tabular}{|c|c|c|c|c|c|c|c|c|c|c|c|c|}
\hline \multirow{2}{*}{$\begin{array}{c}\mathrm{T} \\
\left({ }^{\circ} \mathrm{C}\right)\end{array}$} & \multicolumn{3}{|c|}{$\mathrm{P}(\%)$} & \multicolumn{3}{|c|}{ sf (MPa) } & \multicolumn{3}{|c|}{$1(\mathrm{~W} / \mathrm{mK})$} & \multicolumn{3}{|c|}{$\mathrm{e}\left(\mathrm{Ws}^{0,5} / \mathrm{m}^{2} \mathrm{~K}\right)$} \\
\hline & $\mathrm{A}$ & $\mathrm{B}$ & $\mathrm{C}$ & $\mathrm{A}$ & $\mathrm{B}$ & $\mathrm{C}$ & A & $\mathrm{B}$ & $\mathrm{C}$ & $\mathrm{A}$ & $\mathrm{B}$ & $\mathrm{C}$ \\
\hline 950 & 41 & 40 & 55 & $3.0 \pm 0.6$ & $2.4 \pm 0.1$ & $2.5 \pm 0.2$ & $0.39 \pm 0.02$ & $0.40 \pm 0.02$ & $0.30 \pm 0.01$ & 812 & 837 & 639 \\
\hline 1000 & 38 & 38 & 40 & $8.9 \pm 0.4$ & $9.0 \pm 1.5$ & $18.9 \pm 0.5$ & $0.51 \pm 0.03$ & $0.52 \pm 0.01$ & $0.49 \pm 0.01$ & 953 & 967 & 942 \\
\hline 1100 & 33 & 30 & 42 & $24.7 \pm 0.3$ & $26.3 \pm 2.2$ & $23.8 \pm 1.7$ & $0.71 \pm 0.01$ & $0.70 \pm 0.03$ & $0.44 \pm 0.03$ & 1183 & 1180 & 860 \\
\hline 1170 & 29 & 35 & 64 & $38.7 \pm 0.7$ & $21.5 \pm 1.4$ & $10.4 \pm 1.4$ & $0.96 \pm 0.03$ & $0.65 \pm 0.02$ & $0.40 \pm 0.02$ & 1489 & 1082 & 654 \\
\hline 1200 & 17 & 44 & 76 & $45.2 \pm 2.4$ & $14.9 \pm 0.2$ & $3.0 \pm 0.5$ & $1.06 \pm 0.02$ & $0.53 \pm 0.03$ & $0.29 \pm 0.01$ & 1565 & 903 & 437 \\
\hline 1250 & 38 & 62 & 68 & $21.9 \pm 0.8$ & $6.0 \pm 0.8$ & $4.9 \pm 0.7$ & $0.69 \pm 0.03$ & $0.39 \pm 0.01$ & $0.20 \pm 0.02$ & 1099 & 637 & - \\
\hline
\end{tabular}


can be seen that the residue $(\mathrm{C})$ and ceramic powder $(\mathrm{A})$ contribute significantly for such effects.

This behavior can be related to the formed glassy phase at high temperatures but in particular to some contaminations from the polishing disc which has organic materials and silicon carbide.

\subsection{Microstructural characterization of the ceramic samples}

According to the ceramic samples compacted at $30 \mathrm{MPa}$, without and with 20 wt. (\%) residue incorporation (Figure 4), it can be verify that by changing the firing temperature and residue content it is possible to obtain porous ceramic floor tiles. The introduction of a contact resistance (crustiness surface) improves the thermal comfort.

From the SEM micrographs (Figure 5) it can be seen that from 1100 to $1170{ }^{\circ} \mathrm{C}$ the residue is included in the ceramic body matrix. However, from 1200 to $1250{ }^{\circ} \mathrm{C}$ the residue apparently was melted originating porosity, which increased as the firing temperature was increased. In this last case, i.e., for samples heat-treated at $1250{ }^{\circ} \mathrm{C}$, an expansion was also observed.
Already through the image of Figure 6 obtained by optical microscope it can be observed a ceramic sample formed only by the residue subjected to burn in $1250{ }^{\circ} \mathrm{C}$. Regarding the porosity, it can verify that the pores are mostly closed and rounded, which may explain the proper mechanical resistance of the product, despite its low density.

\subsection{Thermal and mechanical characterization of the ceramic samples}

Table 2 shows the average values of the results of thermal properties, mechanical and physical measures to five tiles compacted at $30 \mathrm{MPa}$ without residue (A), with the incorporation of $20 \%$ of residue (B) and samples with $100 \%$ of residue (C) and variation of firing temperature from 950 to $1250{ }^{\circ} \mathrm{C}$. The introduction of porosity in the tiles is one of the factors responsible for reduction of mechanical resistance and low thermal effusivity that is directly correlated with the thermal conductivity ${ }^{5}$ and apparent density. From the point of view heat as less is the thermal effusivity more comfortable will be ceramic sample.

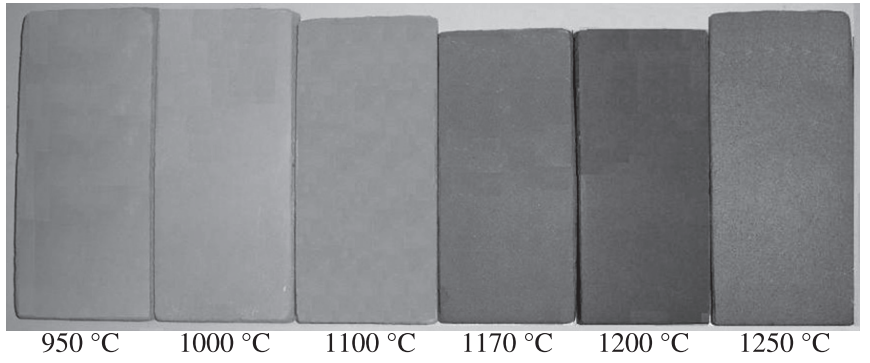

(a)

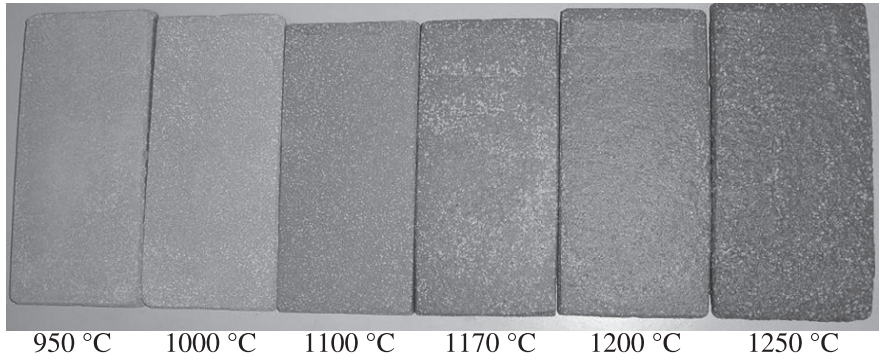

(b)

Figure 4. Sintered ceramic substrates at temperatures of $950,1000,100,1170,1200$ and $1250{ }^{\circ} \mathrm{C}$ of: a) atomized mass; and b) atomized mass with the incorporation of $20 \mathrm{wt}$. (\%) of residue.

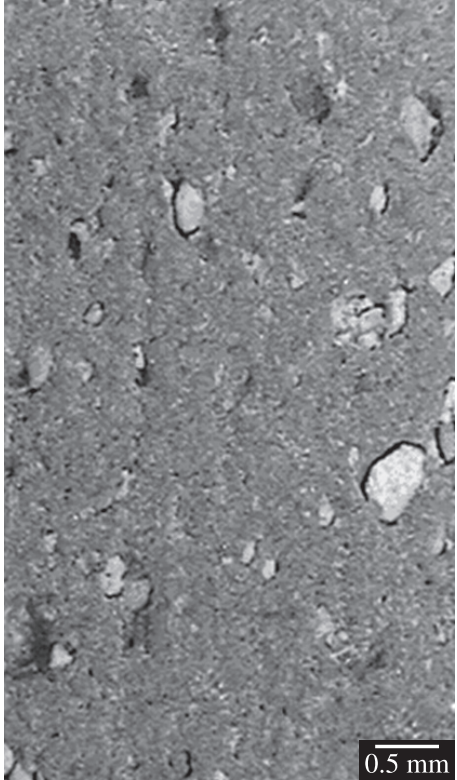

$1100{ }^{\circ} \mathrm{C}$

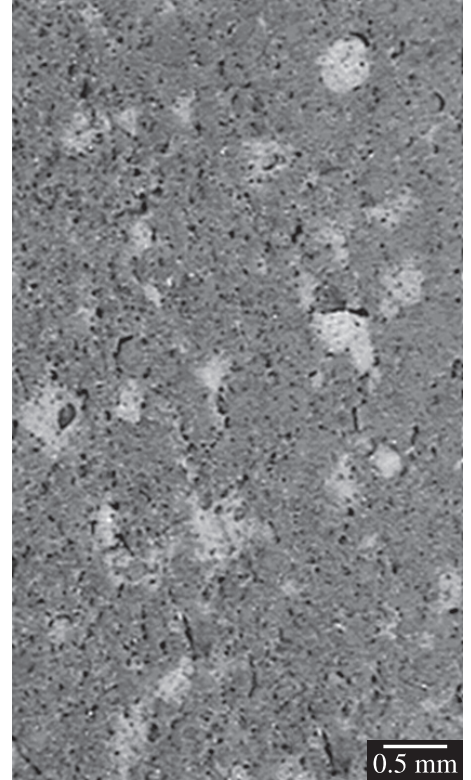

$1170^{\circ} \mathrm{C}$

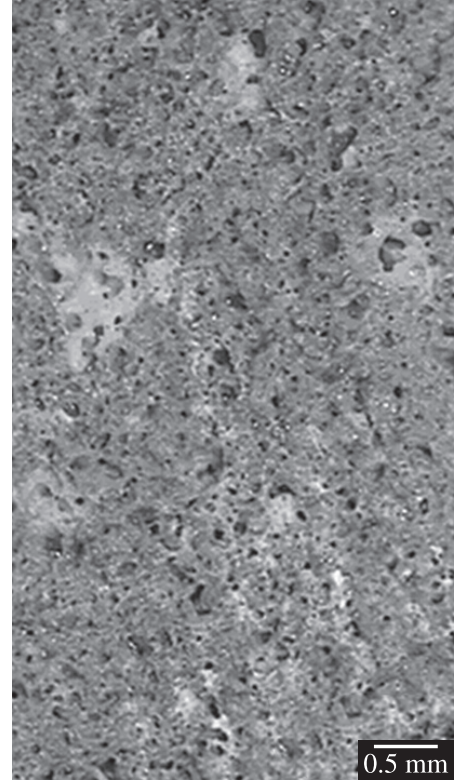

$1200^{\circ} \mathrm{C}$

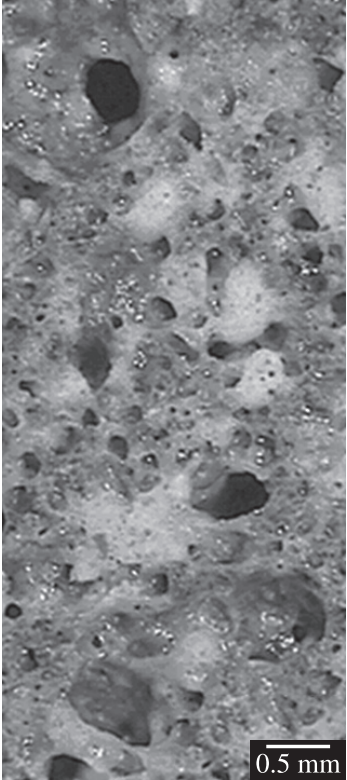

$1250{ }^{\circ} \mathrm{C}$

Figure 5. SEM micrographs of samples with $20 \mathrm{wt}$. (\%) residue fired at $1100,1170,1200$ and $1250{ }^{\circ} \mathrm{C}$ 


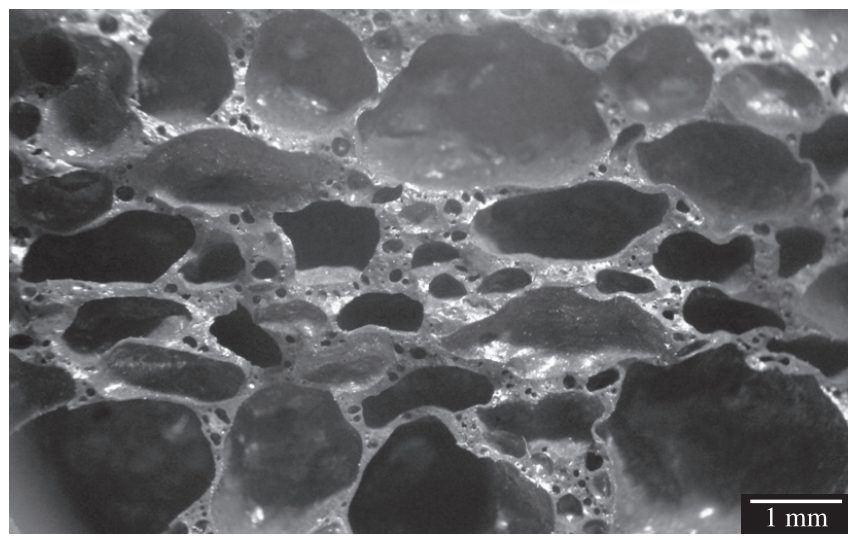

Figure 6. SEM micrograph of a $100 \%$ residue ceramic sample after compaction and firing to $1250{ }^{\circ} \mathrm{C}$.

\section{Conclusions}

The thermal sensation of cold or hot depends on the environmental conditions and material properties including its microstructure and crustiness surface. The introduction of a contact resistance (crustiness surface) improves the thermal comfort.

Combined appropriately raw materials and by changing firing temperature of samples with $20 \mathrm{wt}$. (\%) residues incorporation is possible to obtain porous ceramic floor tiles with optimized properties for a given application.

Regarding the thermal, physical and mechanical characterization of the ceramic samples the introduction of porosity in the ceramic samples resulted in decreased mechanical resistance and low thermal effusivity that is directly correlated with the thermal conductivity and apparent density. From the point of view heat as less is the thermal effusivity more comfortable will be ceramic sample.

According to ISO $13006^{6}$, the ceramic floor tiles obtained without residue incorporation (product semi-gres) should possess flexure resistance equal or higher at $22 \mathrm{MPa}$. Even with the porosity generation being varied the firing temperature, samples presented flexure resistance equal or higher at $22 \mathrm{MPa}$ with 20 and $100 \mathrm{wt}$. (\%) of residue and at $1100{ }^{\circ} \mathrm{C}$.

Through differential thermal analysis of the residue (DTA), it can be verify at $1100{ }^{\circ} \mathrm{C}$ a peak on the early stages of the melting of phase vitreous present in the sample, and probably the beginning of the softening of the residue. Thus, the ceramic samples compacted to $1100{ }^{\circ} \mathrm{C}$ with the incorporation of $100 \mathrm{wt}$. (\%) of residue showed the greatest value for the mechanical strength.

Regarding the microstructural characterization of the ceramic samples, it can be verify the increase in the quantity and size of pores to the extent that the amount of residue is increased. It can be observed by the microstructure of ceramic samples with $20 \%$ of residue and by changing firing temperature of $1100{ }^{\circ} \mathrm{C}, 1170{ }^{\circ} \mathrm{C}, 1200{ }^{\circ} \mathrm{C}$ and $1250{ }^{\circ} \mathrm{C}$, that the residue particles appear detached from the matrix of atomized mass. From the temperature of $1170{ }^{\circ} \mathrm{C}$ it can be noted that there was the process of sintering promoting the connection of the particles. Already in $1250{ }^{\circ} \mathrm{C}$, there was an expansion of the ceramic substrate, and therefore a higher porosity.

\section{References}

1. Xavier AAP. Predição de conforto térmico em ambientes internos com atividades sedentárias-Teoria física aplicada a estudos de campo [Tese de Doutorado]. Florianópolis: Universidade Federal de Santa Catarina, 2000.

2. Thermal Comfort. In: Ashrae Fundamentals. Atlanta, 1997. chap 8.

3. Fanger PO. Thermal Comfort. New York: McGraw-Hill Book Company, 1970.

4. Rhee SK. Porosity. Thermal Conductivity Correlations for Ceramic Materials. Materials Science and Engineering. 1975; 20:89-83.

5. International Organization for Standardization. ISO 8301. Standard Test Method for Steady-State Heat Flux Measurements and Thermal Transmission Properties by Means of the Heat Flow Meter Apparatus. 1991

6. International Organization for Standardization. ISO 13006. Ceramic tile-Definitions, classification, characteristics and marking. 1995. 
